\title{
Extracting and overlaping geospatial informations from remote sensing to mapping genegal drought of Ninh Thuan province
}

\author{
Thao Phuong Thi Do ${ }^{1}$, Chinh Mai Thi Duong ${ }^{2}$, Tai Anh Le ${ }^{2}$, Vinh Tuyet Thi Tran ${ }^{1}$, \\ Ha Thu Thi Nguyen ${ }^{3}$ \\ ${ }^{1}$ Faculty of Geomatics and Land Administration, Hanoi University of Minning and Geology, Vietnam \\ ${ }^{2}$ Branch of Hanoi University of Natural resources and Environment in Thanh Hoa, Vietnam \\ ${ }^{3}$ Center for National and Administrative Boundaries, Deparment of Survey Mapping and Geographic \\ Information Vietnam, Vietnam
}

ARTICLE INFO ABSTRACT

Article history:

Received $19^{\text {th }}$ June 2020

Revised 03 ${ }^{\text {rd }}$ Aug. 2020

Accepted 31st Aug. 2020

Keywords:

Genegal drought,

NinhThuan,

SAVI,

TCI,

TVDI.
Drought is one of the natural phenomena that seriously affects to society in general as well as the lives of people in particular. Therefore, determining early drought is necessary. Remote sensing and GIS technology with extracting and overlaping tools which can assess the extent of drought from geospatial informations in a wide area. Experimental area is Ninh Thuan province, where drought often occur. Five indexes (TCI, VCI, SAVI, WWSVI, TVDI) are extracted from Landsat 8. The weights according to the level of influence is determine by Analytic Hierarchy Process (AHP). Results shows current drought in five levels: no drought; low; medium; high and very high, then compared with the drought warning system in the South-central region. The areas of Ninh Phuoc, Ninh Son and Phan Rang are higher drought phenomena at the time of dry season (accounting for about $60 \%$ of the total provincial area).

Copyright (C) 2020 Hanoi University of Mining and Geology. All rights reserved.

${ }^{*}$ Corresponding author

E - mail: dothiphuongthao@humg.edu.vn

DOI: 10.46326/JMES.2020.61(4).02 


\section{Tạp chí Khoa học Kỹ thuật Mỏ - Địa chất}

Trang điện tử: http://tapchi.humg.edu.vn

\section{Thành lập bản đồ khô hạn tổng hợp tỉnh Ninh Thuận bằng phương pháp chiết xuất và tổng hợp thông tin địa không gian từ dữ liệu Landsat 8 OLI-TIR}

\section{Đỗ Thị Phương Thảo ${ }^{1,}$, Dương Thị Mai Chinh ${ }^{2}$, Lê Anh Tài ${ }^{2}$, Trần Thị Tuyết Vinh"1, Nguyễn Thị Thu Hà ${ }^{3}$}

${ }^{1}$ Khoa Trắc địa - Bản đồ và Quản lý đất đai , Trường Đại học Mỏ - Địa chất, Việt Nam

${ }^{2}$ Khoa Trắc địa Bản đồ, Phân hiệu Đại học Tài Nguyên Môi truờng Hà Nội tại Thanh Hóa, Việt Nam

${ }^{3}$ Trung tâm Biên giới và Địa giới, Cục Đo đạc Bản đồ và Thông tin Địa lý, Việt Nam

THÔNG TIN BÀI BÁO

Quá trình:

Nhận bài 19/6/2020

Sửa xong 03/8/2020

Chấp nhận đăng 31/8/2020

Tù̀ khóa:

Khô hạn tổng hợp,

Ninh Thuận,

SAVI,

TCI,

TVDI.

\section{TÓM TẮT}

Hạn hán là một trong nhũng hiện tượng tự nhiên có ảnh hưởng nghiêm trọng đến xã hội nói chung và cuộc sống người dân nói riêng. Xác định hiện trang để có biện pháp sớm với tình trạng khô hạ là cần thiết. Công nghệ viễn thám và GIS là một trong nhũng công cu chiết xuất, phân tích thông tin địa không gian ưu việt trong đánh giá mức độ hạn hán trên phạm vi lãnh thổ rộng. Khu vực thực nghiệm là tỉnh Ninh Thuận, nơi thường xuyên xảy ra các hiện tượng hạn hán do thiên tai (hoăc do con người gây ra). Năm chỉ số yếu tố thành phần được chia theo các cấp bậc quan trọng khác nhau chiết xuất tù̀ dũ liệu Landsat 8 và được gán trọng số tùy mức độ ảnh hưởng theo phương pháp phân tích thứ bậc (AHP). Bản đồ kết quả đưa ra được hiện trạng khô hạn thể hiẹn bằng năm mức độ: không khô hạn, khô hạn thấp, trung bình, cao và rất cao, sau đó được so sánh với hệ thống cảnh báo hạn hán khu vực Nam Trung Bộ. Kết quả cho thấy khu vực Ninh Phước, Ninh Sơn, Phan Rang là nơ có hiện tượng khô hạn cao hơn tại thời điểm mùa khô (chiếm khoảng 60\% tổng diện tích tỉnh).

(C) 2020 Trường Đại học Mỏ - Địa chất. Tất cả các quyền được bảo đảm.

\section{Mở đầu}

Khô hạn là một loại thiên tai phổ biến trên thế giới, biểu hiện của nó là lượng mưa thiếu hụt nghiêm trọng, kéo dài, làm giảm hàm lượng độ ẩm trong không khí và hàm lượng nước trong đất, làm

\section{*Tác giả liên hệ}

E- mail: dothiphuongthao@humg.edu.vn DOI: 10.46326/JMES.2020.61(4).02 suy kiệt dòng chảy sông suối, hạ thấp mực nước ao hồ, mực nước trong các tầng chứa nước dưới đất,... có thể kéo dài trong một giai đoạn nhất định trên diện rộng gây ảnh hưởng không nhỏ đến môi trường, kinh tế, chính trị, xã hội và sức khỏe con người.

Khu vực Ninh Thuận có nền nhiệt độ không ổn định, bất thường. Sự gia tăng chênh lệch nhiệt độ ngày đêm theo hướng tăng cao về ban ngày, hạ thấp về ban đêm; hoặc trong một số tháng của 
mùa khô, ở một số nơi đã có hiện tượng nhiệt độ tăng cao đột biến, gây ra hiện tượng nắng nóng hơn bình thường, khiến hạn hán gay gắt, kéo dài. Lượng mưa thiếu hụt khoảng $15 \div 30 \%$ so với trung bình nhiều năm, thậm chí nhiều nơi không có mưa, nguồn nước phục vụ sinh hoạt đang thiếu hụt trầm trọng do nhiều nhà máy cấp nước ngừng hoạt động vì hạn hán (Hoàng Thanh Sơn và nnk., 2014).

Để đánh giá hiện trạng và diễn biến khô hạn tại các tỉnh thường xuyên khô hạn này, đa phần hay dùng phương pháp quan trắc truyền thống, tức là dựa hoàn toàn vào đo lượng mưa nên rất khó thu được số liệu trong thời gian thực dẫn đến việc thực hiện rất khó khăn. Bên cạnh đó, việc đầu tư hệ thống trạm quan trắc mưa còn rất hạn chế, có khu vực không có trạm quan trắc nào (Lê Sâm và Nguyễn Đình Vượng, 2008).

Hiện nay, công nghệ viễn thám đã phát triển mạnh, các số liệu từ vệ tinh với độ phân giải không gian và thời gian linh hoạt có thể được sử dụng để nhận biết sự xuất hiện, thời gian tồn tại và cường độ của hạn hán. Do đó, những số liệu vệ tinh quan trắc trái đất đang được các nước trên thế giới sử dụng rất hiệu quả, cần được quan tâm trong việc đánh giá hiện trạng và diễn biến khô hạn (AghaKouchak và nnk., 2015). Trên thế giới đã có một số tác giả đã sử dụng ảnh Landsat 8 ước tính chỉ số điều kiện nhiệt độ thực vật (VTCI Vegetation Temperature Condition Index) từ nhiệt độ bề mặt (LST - Land Surface Temperature) và chỉ số thực vật (NDVI - Normalized Difference Vegetation Index) để theo dõi hạn hán cho vùng đất ngập nước ở hồ Chad (Châu Phi) giai đoạn $1999 \div 2018$ (Willibroad và Lee, 2019; Rosalena và nnk., 2014) đã lập bản đồ mức độ hạn hán xảy ra ở Bogor Regency (Indonesia) từ năm 2005 đến 2015 bằng cách xác định chỉ số thực vật cấp nước (WSVI) được chiết xuất từ ảnh Landsat 8 OLI TIRS và Landsat 5 TM. Và cũng tại Ethiopia (Châu Phi), Eskinder và nnk.,(2018) đã sử dụng dữ liệu MOD11A2 Terra xác định chỉ số sức khỏe thực vật VHI (Vegetation Health Index) được tính bởi các chỉ số hạn hán LST, NDVI, VCI (Vegetation Condition Index) và TCI (Temperature Condition Index) để giám sát hạn hán nông nghiệp ứng phó với sự thay đổi lượng mưa như thế nào. Trong nước cũng đã có một số nghiên cứu sử dụng ảnh viễn thám để phân tích chất lượng nước mặt trong giải đoán các yếu tố nhiệt độ, khô hạn, cung cấp các thông tin địa không gian trên diện rộng, qua các phép phân tích đánh giá có thể phân vùng được khu vực khô hạn. Tuy nhiên, các nghiên cứu còn chưa có hệ thống, các chỉ số chiết xuất từ ảnh vệ tinh để tổng hợp bản đồ khô hạn còn đơn giản và chưa tính đến trọng số ảnh hưởng riêng biệt của chúng (Trịnh Lê Hùng và Đào Khánh Hoài, 2015; Bùi Quang Huy và nnk., 2016),... còn lại đa phần sử dụng các chỉ số tính toán nội suy từ lượng mưa đòi hỏi dữ liệu quan trắc phải đồng bộ, rất khó có được trong điều kiện thực tiễn của Việt Nam (Vũ Thị Thu Hằng và Trần Thị Thanh Hà, 2013; Trần Văn Tý và nnk., 2015).

Với mong muốn góp phần tìm kiếm phương pháp lập bản đồ khô hạn tổng hợp có hiệu quả, đơn giản và nhanh chóng, bài báo trình bày phương pháp chiết xuất, tổng hợp có trọng số các thông tin địa không gian từ dữ liệu ảnh vệ tinh để thành lập bản đồ khô hạn tỉnh Ninh Thuận, nhằm xác định các khu vực có khả năng khô hạn cao giúp cán bộ sở nông lâm nghiệp, các cơ quan chức năng có thể ngăn ngừa, giảm thiểu hoặc có những biện pháp phòng tránh, hạn chế hiện tượng khô hạn thường xuyên trên địa bàn tỉnh.

\section{Khu vực nghiên cứu và dữ liệu}

\subsection{Khu vực nghiên cúru}

Ninh Thuận là một tỉnh ven biển thuộc vùng Duyên hải Nam Trung Bộ của Việt Nam, có hình thể giống như một hình bình hành, hai góc nhọn ở phía tây bắc và đông nam, có toạ độ địa lý: 11018'14" đến 12009'15" vĩ độ bắc, 108009'08" đến 109014'25" kinh độ đông (Hình 1). Địa hình thấp dần từ tây bắc xuống đông nam, được bao bọc bởi 3 mặt núi và đồng bằng ven biển. Đồi núi chiếm $63,2 \%$ diện tích của tỉnh, chủ yếu là núi thấp, cao trung bình từ $200 \div 1.000 \mathrm{~m}$, đồi gò bán sơn địa chiếm 14,4\% và đồng bằng ven biển chiếm 22,4\% diện tích đất tự nhiên.

Ninh Thuận có khí hậu với đặc trưng khô nóng, gió nhiều, bốc hơi mạnh do hệ thống núi ở Tây Nguyên và ở Bình Thuận đã cản những cơn gió mùa tây nam - đông bắc không mang mưa đến được và vào Ninh Thuận thì biến thành khô hanh. Nhiệt độ trung bình hàng năm từ $26 \div 27^{\circ} \mathrm{C}$, lượng mưa trung bình $700 \div 800 \mathrm{~mm}$. Nguồn nước phân bổ không đều, tập trung chủ yếu ở khu vực phía Bắc và trung tâm tỉnh. Nguồn nước ngầm trong địa bàn tỉnh chỉ bằng $1 / 3$ mức bình quân cả nước. 


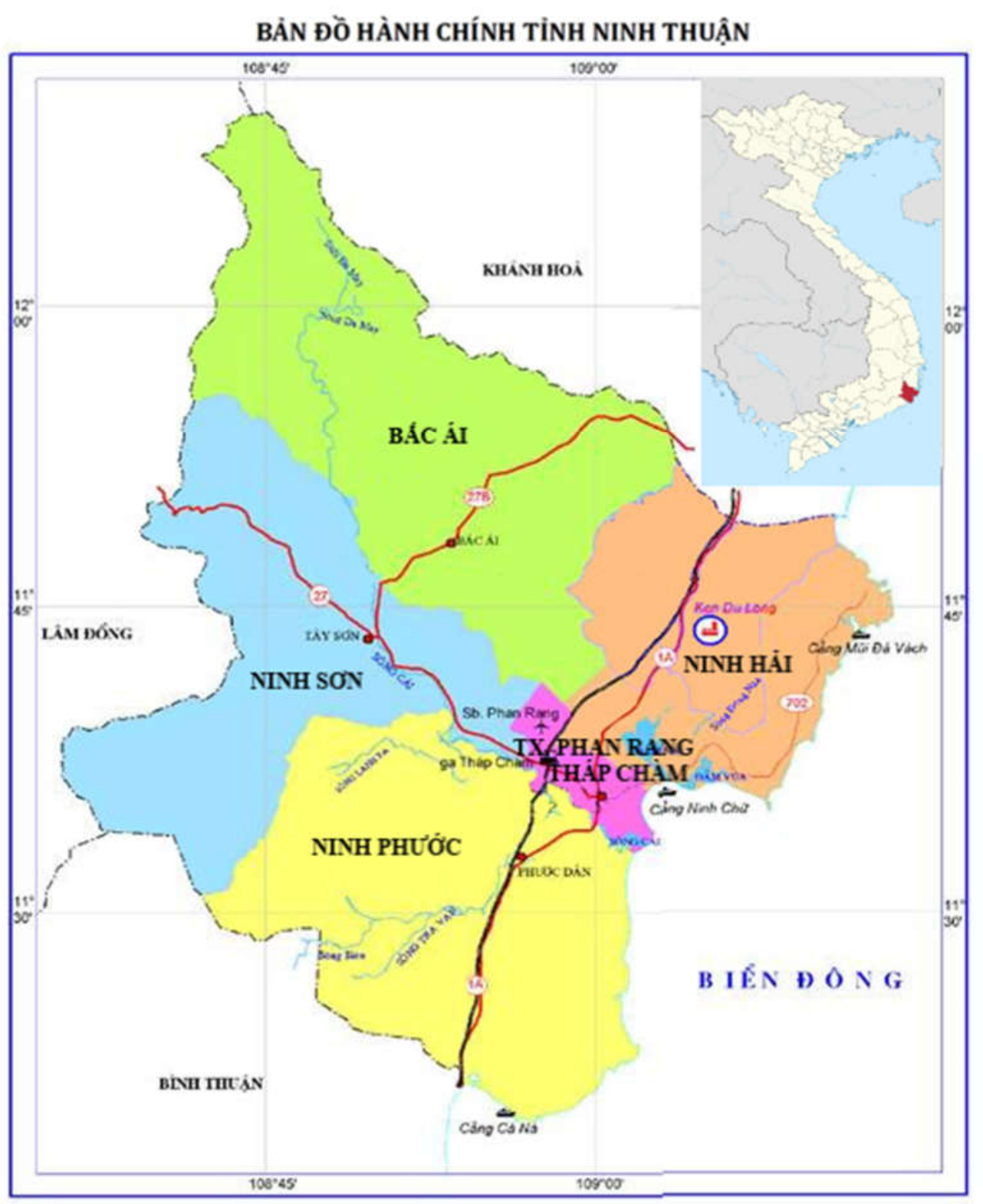

Hình 1. Khu vực nghiên cúu tỉnh Ninh Thuận.

Tổng số diện tích đất hoang mạc ở Ninh Thuận là 41.021 ha, chiếm 12,21\% diện tích đất tự nhiên toàn tỉnh. Cho đến hiện nay thực trạng hoang mạc hóa vẫn tiếp tục có chiều hướng gia tăng. Hàng năm, vào mùa khô (từ tháng 12 đến tháng 9) tình trạng hạn hán, thiếu nước thường xuyên xảy ra, làm ảnh hưởng nghiêm trọng đến sản xuất và các hoạt động kinh tế của địa phương (Hoàng Thanh Sơn và nnk., 2014).

\subsection{Dũ̃ liêu}

Dữ liệu chính dùng trong nghiên cứu này là ảnh viễn thám Landsat 8 OLI_TIR được chọn với lợi thế có bổ sung thêm 2 kênh phổ trong đó một kênh cho phép phát hiện mây nhỏ và chỉnh sửa các hiệu ứng khí quyển, kênh còn lại cho phép thu thập thông tin ở tầng nước sâu. Mặt khác, kênh hồng ngoại của Landsat 8 được chia làm 2 cho phép xác định nhiệt độ chính xác hơn. Số hiệu cảnh ảnh của tỉnh Ninh Thuận là: LC08 - L1TP - 123052 - 2018 1102 - 20181115 - 01 - T1 chụp ngày 15/11/ 2018 vào đầu mùa khô là mùa hay xảy ra hạn hán, được tải về từ trang điện tử của cơ quan địa chất Hoa Kỳ (USGS). Ngoài ra, dữ liệu bản đồ chuyên đề về khô hạn vùng Tây Nguyên và các tỉnh Nam Trung Bộ do Viện công nghệ Vũ trụ thành lập năm 
2016 cùng thời điểm mùa khô cũng được sử dụng như là tài liệu hỗ trợ trong quá trình kiểm tra so sánh kết quả sau thành lập bản đồ.

\section{Phương pháp nghiên cứu}

Tín hiệu nhiệt của vật chất được thu nhận bởi các bộ cảm biến nhiệt. Các bộ cảm biến ghi nhận cường độ bức xạ điện từ bề mặt đất được thể hiện theo giá trị số nguyên (Digital Number - DN) với mỗi kênh. Do vậy, để xác định các chỉ số từ ảnh viễn thám, bước đầu tiên phải tiến hành hiệu chỉnh bức xạ để chuyển đổi giá trị số nguyên của ảnh Landsat về giá trị thực của bức xạ điện từ $\left(\mathrm{Wm}^{-2} \mu \mathrm{m}^{-1}\right)$.

Với ảnh Landsat 8 OLI, giá trị bức xạ được xác định như sau:

$$
L_{\lambda}=M_{L} Q_{c a l}+A_{L}
$$

Trong đó: $L_{\lambda}$ - giá trị bức xạ phổ (Spectral Radiance); $M_{L}, A_{L}$ - hệ số chuyển đổi, được cung cấp trong file metadata ảnh Landsat 8; Qcal - giá trị số của kênh ảnh.

\subsection{Chiết xuất thông tin địa không gian tù̀ dũ liệu viễn thám}

3.1.1. Chiết xuất các thông tin địa không gian về nhiệt độ bề mặt

- Phương pháp xác định nhiệt độ bề mặt LST (Land Surface Temperature)

Nhiệt độ bề mặt là một biến quan trọng trong nhiều tính toán ứng dụng, là chỉ thị của tình trạng nhiệt động lực gây nên bởi cân bằng nhiệt của các thông lượng giữa khí quyển, bề mặt và lớp đất mặt phụ. Xác định nhiệt độ bề mặt (LST) theo công thức:

$$
L S T=\frac{T_{B}}{1+\left(\frac{\lambda \cdot T_{B}}{\rho}\right) \cdot \ln \varepsilon}
$$

Trong đó: $T_{B}$ - giá trị nhiệt độ bức xạ của ảnh (Đơn vị Kelvin). $T_{B}$ được tính theo công thức:

$$
T_{B}=\frac{K_{2}}{\ln \left(\frac{K_{1}}{L_{\lambda}}+1\right)}
$$

Trong đó: $K_{1}, K_{2}$ - hằng số được cung cấp trong file metadata của ảnh Landsat; $\lambda$ - giá trị bước sóng trung tâm kênh hồng ngoại nhiệt; $\rho=\frac{h \cdot c}{\sigma}$, với $\sigma$ là hằng số Stefan - Boltzmann $\left(1,38.10^{-23}\right), h$ là hằng số Plank $\left(6,626.10^{-34} \mathrm{~J} . s\right), c$ là vận tốc ánh sáng $\left(2,998.10^{8} \mathrm{~m} / \mathrm{s}\right) ; \varepsilon$ - độ phát xạ bề mặt (Surface Emissivity), được tính theo công thức:

$$
\varepsilon=\varepsilon_{V} P_{V}+\varepsilon_{S}\left(1-P_{V}\right)
$$

Trong đó: $\varepsilon_{v}, \varepsilon_{s}$ - độ phát xạ đặc trưng cho đất và thực vật thuần nhất; $P_{v}$ - tỉ lệ thực vật trong một pixel.

$$
P_{V}=\left[\left(N D V I-N D V I_{\min }\right) /\left(N D V I_{\max }-N D V I_{\min }\right)\right]^{2}
$$

- Xác định chỉ số tình trạng nhiệt độ TCI (Temperature Condition Index)

TCI là chỉ số được sử dụng để xác định các tình huống hạn hán liên quan đến nhiệt độ. Chỉ số này giả định rằng trong thời gian hạn hán, độ ẩm của đất giảm đáng kể và gây ảnh hưởng đến thực vật. Khi nhiệt độ cao hoặc hạn hán tăng, thực vật sẽ có xu hướng suy giảm trong thời kỳ sinh trưởng. Khi nhiệt độ thấp hoặc khả năng hạn hán thấp, đa phần sẽ thuận lợi cho thảm thực vật trong quá trình phát triển (Eskinder và nnk., 2018). TCI được xác định theo công thức:

$$
T C I=100 * \frac{L S T_{\max }-L S T}{L S T_{\max }-L S T_{\min }}
$$

Trong đó: $L S T_{\max } L S T_{\min }$ - giá trị nhiệt độ bề mặt lớn nhất và nhỏ nhất.

3.1.2. Chiết xuất các thông tin địa không gian về thực vật

- Chỉ số thực vật NDVI (Normalized Difference Vegetation Index)

$$
N D V I=\frac{N I R-R E D}{N I R+R E D}
$$

Trong đó: NIR - kênh cận hồng ngoại; RED kênh đỏ.

NDVI sẽ có giá trị trong khoảng $[-1,1]$, trên thực tế giá trị của NDVI sẽ tiến dần về 0 nếu không có cây xanh và tiến dần về 1 nếu khu vực đó có mật độ thực vật cao.

Chỉ số NDVI cho biết, nếu bức xạ gần hồng ngoại được phản xạ nhiều hơn bức xạ nhìn thấy, thực vật ở điểm ảnh (pixel) đó sẽ rậm rạp, dày đặc hơn, nếu không có sự khác biệt nhiều trong phản xạ giữa kênh gần hồng ngoại với kênh nhìn thấy thì thực vật khu vực đó nghèo nàn, có thể chỉ có đồng cỏ, cây bụi hoặc hoang mạc (AghaKouchak và nnk., 2015). 
- Chỉ số thực vật có hiệu chỉnh ảnh hưởng của đất SAVI (Soil Adjusted Vegetation Index)

SAVI được thiết kế để giảm thiểu ảnh hưởng độ sáng của đất, được sử dụng để ước tính hoạt động quang hợp của thảm thực vật và theo dõi hạn hán. SAVI được biến đổi từ công thức tính NDVI với tham số L được thêm vào để tăng độ chính xác cho những vùng có độ che phủ thấp. SAVI cũng như NDVI chủ yếu là theo dõi kết quả của sự thiếu hụt lượng mưa, sự khác biệt giữa thoát hơi nước thực tế và tiềm năng, nhiệt độ cao và thiếu hụt nước trong đất. Hạn hán do lượng mưa không đều hoặc giảm hoặc nhiệt độ tăng làm giảm NDVI và SAVI trong các khu vực của thảm thực vật, do vậy chỉ số SAVI cung cấp thông tin rất hữu ích cho việc theo dõi hạn hán (AghaKouchak và nnk., 2015).

$$
S A V I=\frac{N I R-R E D}{N I R+R E D+L}(L+1)
$$

Trong đó: NIR - kênh cận hồng ngoại; RED kênh đỏ; $L$ - hệ số diều chỉnh độ sáng đất, thông thường là 0.5

- Chỉ số trạng thái thực vật VCI (Vegetation Condition Index)

Giá trị của VCI phản ánh thực vật phát triển hoặc xuống cấp đến mức nào khi ứng phó với thời tiết. Giá trị của VCI đo bằng phần trăm trong khoảng từ 0 đến 100 . Giá trị cao của VCI biểu thị điều kiện thực vật khỏe mạnh và khu vực này không hạn hán. Giá trị VCI dao động trong khoảng $50 \%$ : thực vật phát triển bình thường, $\mathrm{VCI}>50 \%$ : thực vật phát triển tốt và khi VCI đạt gần mức 100\% là khi thực vật phát triển tốt nhất (Eskinder và nnk., 2018). Chỉ số trạng thái thực vật VCI được xác định theo công thức:

$$
V C I=100 * \frac{N D V I-N D V I_{\min }}{N D V I_{\max }-N D V I_{\min }}
$$

Trong đó: $N D V I_{\max }$ - giá trị chỉ số thực vật lớn nhất; $N D V I_{\min }$ - giá trị chỉ số thực vật nhỏ nhất.

- Chỉ số cấp nước thực vật WSVI (Water SupplyingVegetation Index)

Chỉ số cấp nước thực vật WSVI là một trong những chỉ số kết hợp giữa chỉ số thực vật NDVI và nhiệt độ bề mặt LST để xác định điều kiện ẩm của đất. Khi hạn hán xảy ra, phạm vi giá trị của WSVI nằm trong khoảng $-4,2 \div+4,2$, giá trị nhỏ hơn của chỉ số có nghĩa là nguồn cung cấp nước thực vật ít hơn và hạn hán nghiêm trọng hơn. Tương tự, giá trị lớn hơn có nghĩa là hạn hán ít nghiêm trọng hơn (Rosalena và nnk., 2014). Chỉ số cấp nước thực vật WSVI được xác định theo công thức tính:

$$
W S V I=\frac{N D V I}{L S T}
$$

Trong đó: NDVI - chỉ số thực vật; $L S T$ - nhiệt độ bề mặt.

- Chỉ số khô hạn nhiệt độ - thực vật TVDI (Temperature Vegetation Dryness Index)

Chỉ số khô hạn nhiệt độ vật sử dụng mối quan hệ giữa nhiệt độ bề mặt và độ ẩm của đất (độ ẩm tương đối) để phản ánh mức độ hạn hán do vậy TVDI xem xét toàn diện mối quan hệ và thay đổi giữa NDVI và LST. Thiếu nước cây cối vẫn có thể xanh lúc ban đầu nhưng nhiệt độ bề mặt có thể tăng lên nhanh chóng với tình trạng thiếu nước. Kết hợp giữa nhiệt độ và NDVI có thể cung cấp thông tin về thực vật và độ ẩm ở điều kiện bề mặt (Eskinder và nnk., 2018; Rosalena và nnk., 2014; AghaKouchak và nnk., 2015; Trịnh Lê Hùng, 2015).

Giá trị của TVDI là $[0,1]$. Giá trị này càng lớn, độ ẩm của đất càng thấp, mức độ hạn hán sẽ càng cao và ngược lại. TVDI được xác định theo công thức:

$$
T V D I=\frac{L S T-L S T_{\min }}{a+b \cdot N D V I-L S T_{\min }}
$$

Trong đó: $N D V I$ - chỉ số thực vật; $L S T_{\min }$ - nhiệt độ bề mặt cực tiểu tương ứng với mỗi khoảng giá trị của NDVI; LST - nhiệt độ tại pixel cần tính; $L S T_{\max }$ - nhiệt độ bề mặt cực đại tương úng với mỗi khoảng giá trị của NDVI; $a, b$ - hệ số trong phương trình tuyến tính của $L S T_{\max }$ với chỉ số thực vật NDVI.

\subsection{Xác định trọng số và chồng gộp các bản đồ thành phần}

\subsubsection{Xác định trọng số}

Tầm quan trọng của các bản đồ chỉ số thành phần được quyết định bằng cách xác định trọng số các yếu tố ảnh hưởng. Nhóm nghiên cứu sử dụng kỹ thuật phân tích thứ bậc AHP (Analytic Hierarchy Process) để xác định trọng số. AHP là phương pháp được phát triển bởi Saaty (1977), đây là một công nghệ mạnh sử dụng trong việc ra các quyết định phức tạp và sử dụng rộng rãi trong 
phân tích dựa trên GIS. Một ma trận so sánh cặp được sử dụng để ước lượng trọng số của các biến. Tầm quan trọng của các biến được các chuyên gia cho điểm so sánh theo cặp. Các số liệu quy mô để so sánh tầm quan trọng của các biến thể hiện trong Hình 2. AHP cũng cung cấp cách xác định mức độ nhất quán của các chuyên gia thông qua tỉ số nhất quán (Consistency Ratio, CR) phải nhỏ hơn hoặc bằng $10 \%$ thì ma trận so sánh cặp mới được sử dụng còn nếu giá trị CR này lớn hơn $10 \%$ thì cần phải thẩm định lại quá trình so sánh cặp hoặc loại bỏ ý kiến.

\subsubsection{Chồng gộp bản đồ}

Bản đồ khô hạn tổng hợp được chồng gộp có trọng số dựa trên các bản đồ chỉ số thành phần: TDVI, WSVI, VCI, SAVI, TCI theo phương pháp trung bình trọng số với sơ đồ phương pháp trình bày trong Hình 3. Công thức tổng quát như sau:

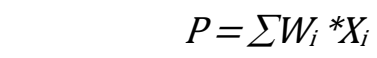

Trong đó: $P$ - chỉ số hạn hán; $W_{i}$ - trọng số của các bản đồ chỉ số thành phần $i ; X_{i}$ - điểm mức độ hạn hán các bản đồ chỉ số thành phần $i$.

\section{Kết quả và thảo luận}

\subsection{Các bản đồ chỉ số thành phần}

Nhiệt độ và chỉ số thực vật NDVI đã được sử dụng rộng rãi nhất để theo dõi hạn hán. Tuy nhiên, riêng dữ liệu nhiệt độ hay NDVI không thể cho thấy đầy đủ mức độ nghiêm trọng của hạn hán nhưng các dữ liệu này (Eskinder Gidey và nnk., 2018) được sử dụng làm đầu vào để tính toán TCI, VCI, SAVI, TVDI và WSVI là mô hình tích hợp giám sát hạn hán tiên tiến theo Hình 3. Các bản đồ này được chuẩn hóa (gán điểm) cho theo đặc điểm của từng tiêu chí, thang bậc phân cấp theo mức độ hạn hán ở Bảng 1.

\subsubsection{Bản đồ chỉ số tình trạng nhiệt độ TCI}

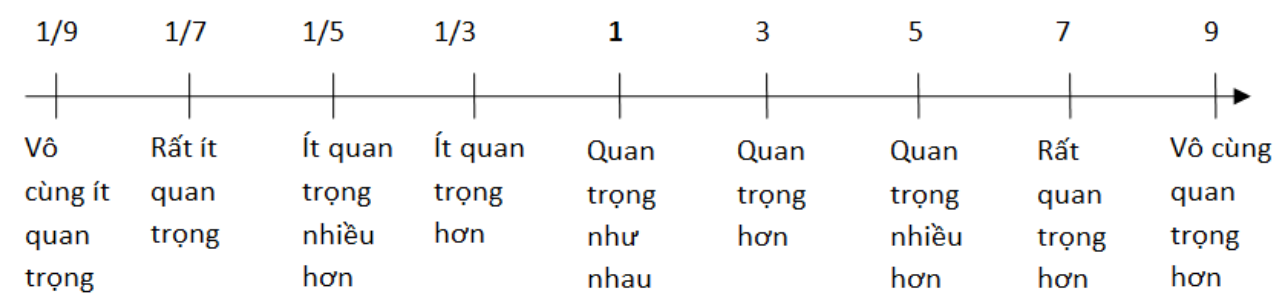

Với điểm 2, 4, 6,8 là trung gian giữa các mức nêu trên

Hình 2. Cách cho điểm so sánh cặp trong phương pháp AHP.

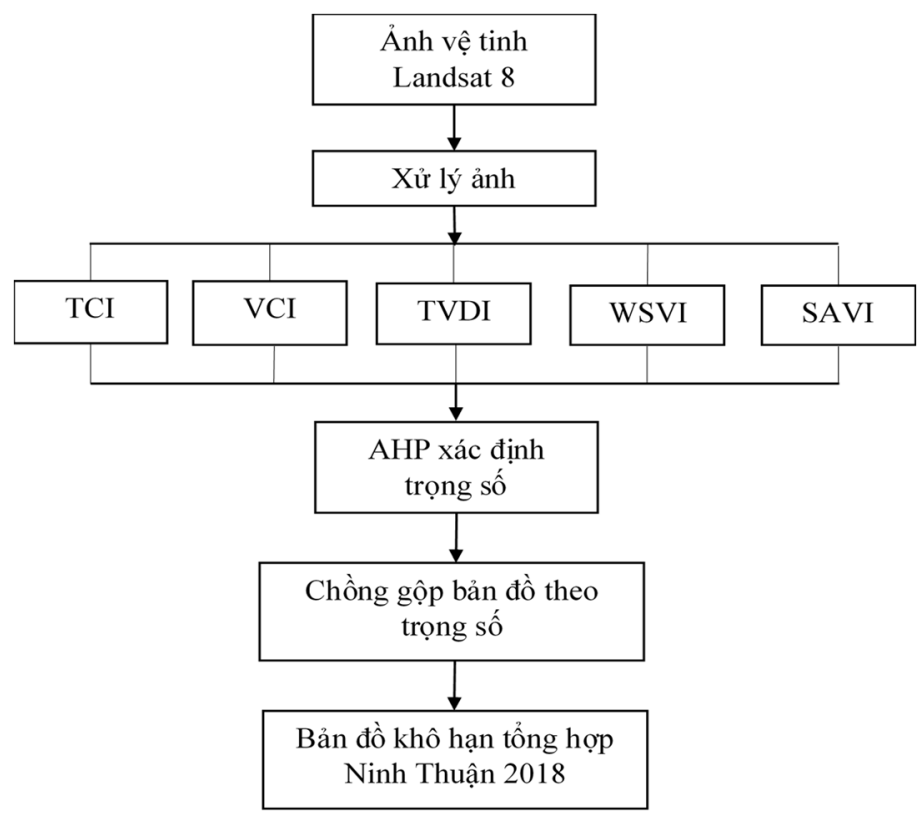

Hình 3. Sơ đồ phương pháp thành lập bản đồ khô hạn tổng hợp tỉnh Ninh Thuận. 
Bảng 1. Bảng phân cấp mức độ khô hạn với các chỉ số.

\begin{tabular}{|c|c|c|c|c|c|}
\hline Mức độ khô hạn & TCI (\%) & VCI (\%) & SAVI & TVDI & WSVI \\
\hline Không khô hạn & $50 \div 100$ & $60 \div 100$ & $>0,28$ & $0 \div 0,2$ & $>0,015$ \\
\hline Khô hạn nhẹ & $30 \div 50$ & $50 \div 60$ & $0,15 \div 0,28$ & $0,2 \div 0,4$ & $0 \div 0,015$ \\
\hline Khô hạn & $20 \div 30$ & $35 \div 50$ & $0,13 \div 0,15$ & $0,4 \div 0,6$ & $-0,01 \div 0$ \\
\hline Khô hạn nặng & $10 \div 20$ & $20 \div 35$ & $0,1 \div 0,13$ & $0,6 \div 0,8$ & $-0,02 \div-0,01$ \\
\hline Khô hạn cực kỳ nặng & $<10$ & $<20$ & $<0,1$ & $0,8 \div 1,0$ & $<-0,02$ \\
\hline
\end{tabular}

TCI là thước đo sự phân bổ nhiệt độ trong khu vực tính theo phần trăm (\%). Giá trị TCI dao động trong khoảng $50 \%$ là mức nhiệt trung bình, TCI > $50 \%$ thì nhiệt độ bắt đầu giảm và khi TCI đạt gần mức $100 \%$ là khi nhiệt độ vùng đó là thấp. Do đó, giá trị TCI thấp tương ứng với sức sống thực vật giảm do khô hạn hoặc thời tiết khắc nghiệt bởi điều kiện nhiệt độ cao. Tại khu vực Ninh Thuận TCI được chuẩn hóa và phân cấp như Bảng 1 , khô hạn tập trung chủ yếu ở huyện Ninh Sơn và Ninh Phước (Hình 4a), đặc biệt ở các xã Mỹ Sơn (Ninh Sơn), Phước Nam, Phước Hưu, Phước Dinh (Ninh Phước).

\subsubsection{Bản đồ chỉ số VCI}

Giá trị VCI tại Ninh Thuận cao tại phía bắc của huyện Bắc Ái và Ninh Hải; phía tây nam của Ninh Sơn và tây bắc của Ninh Phước điều đó chứng tỏ các nơi này điều kiện bình thường hoặc ẩm ướt, không có hạn hán. Các giá trị $35 \div 50 \%$ (màu vàng) thể hiện diện tích hạn hán vừa phải, giá trị VCI trong khoảng $20 \div 35 \%$ (màu cam) thể hiện tỷ lệ hạn hán nghiêm trọng và giá trị VCI nhỏ hơn $20 \%$ cho thấy hạn hán rất nghiêm trọng trong khu vực (Hình 4b).

\subsubsection{Bản đồ chỉ số SAVI}

SAVI thích hợp với các khu vực khô cằn, thảm thực vật thưa thớt hoặc bề mặt đất lộ ra. Trên khu vực Ninh Thuận, theo tính toán từ SAVI, khô hạn nặng chủ yếú tập trung tại khu vực huyện Ninh Phước (Hình 4c).

\subsubsection{Bản đồ chỉ số WSVI}

Trong kết quả chiết tách và xử lý dữ liệu, sử dụng màu sắc và chuẩn hóa phân bậc để cho biết mức độ ẩm được tạo ra từ WSVI. Độ ẩm tỷ lệ nghịch với mức độ hạn hán. Màu đỏ càng hiển thị nhiều thì hạn hán càng cao, đa số vẫn tập trung tại huyện Ninh Phước. Toàn tỉnh Ninh Thuận có giá trị WSVI thấp nhất là $-0,02$ và giá trị cao nhất là
0,015. Các mức độ hạn hán được chuẩn hóa như Hình 4d.

\subsubsection{Bản đồ chỉ số TVDI}

Phân cấp mức độ khô hạn bề mặt đối với chỉ số khô hạn nhiệt độ - thực vật TVDI được trình bày trong Bảng 1. Trong đó, giá trị TVDI nhỏ hơn 0,2 tương ứng với các vùng không có nguy cơ hạn hán, trên bản đồ tỉnh Ninh Thuận khu vực này rất ít và nằm rải rác tại nơi bề mặt có nước, thực vật tười tốt hoặc đất nông nghiệp ngập nước. Chỉ số TVDI trong khoảng $0,2 \div 0,4$ tương ứng với các khu vực ít có nguy cơ khô hạn như khu vực phía bắc của huyện Bác Ái, phía đông của huyện Ninh Hải và phía Tây của huyện Ninh Sơn; chỉ số TVDI trong khoảng $0,4 \div 0,6$ tương ứng với các khu vực khô hạn trung bình thể hiện bằng màu vàng trên bản đồ; chỉ số trong khoảng $0,6 \div 0,8$ là rất khô hạn, tập trung tại các khu vực trung tâm của tỉnh và giá trị chỉ số TVDI lớn hơn 0,8 khu vực có mức độ cực kỳ khô hạn, tập trung tại phía đông huyện Ninh Phước (Hình 4e).

\subsection{Bản đồ khô hạn tổng hợp Ninh Thuận}

Bản đồ khô hạn tổng hợp (Hình 4f) là một bản đồ kết hợp của cả dữ liệu khách quan cũng như chủ quan (ý kiến đánh giá từ chuyên gia). Bản đồ các yếu tố thành phần sẽ được cho điểm, phân tích AHP và nhân trọng số. Trọng số các mức quan trọng ảnh hưởng đến khu vực khác nhau, ở mức độ thứ nhất của hệ thống phân cấp là TVDI, WSVI, sau đó là VCI, SAVI, cuối cùng là ảnh hưởng của TCI (Bảng 2). Các trọng số này được tính toán dựa trên ma trận kết hợp các phán đoán thu được từ các chuyên gia về lĩnh vực địa lý, có tỷ lệ nhất quán thấp hơn 0,1 cho khu vực nghiên cứu nên hoàn toàn tin cậy được. Chồng gộp bản đồ bằng công nghệ GIS theo mô hình sau:

$$
\begin{gathered}
B \bigoplus_{k h t h}=0.22^{*} W S V I+0.16^{*} S A V I+0.19^{*} V C I+ \\
0.33^{*} T V D I+0.1 * T C I
\end{gathered}
$$


Bảng 2. Ma trận ý kiến chuyên gia và trọng số tính được.

\begin{tabular}{|l|l|l|l|l|l|l|}
\hline & WSVI & SAVI & VCI & TVDI & TCI & Trọng số \\
\hline WSVI & 1 & 1,5 & 1,33 & 0,5 & 2,5 & 0,22 \\
\hline SAVI & 0,67 & 1 & 0,5 & 0,75 & 1,66 & 0,16 \\
\hline VCI & 0,75 & 2 & 1 & 0,25 & 2,5 & 0,19 \\
\hline TVDI & 2 & 1,33 & 4 & 1 & 1,25 & 0,33 \\
\hline TCI & 0,4 & 0,6 & 0,4 & 0,4 & 1 & 0,10 \\
\hline
\end{tabular}

(a) BÄN ĐÒ CHİ SÓ TCI TİNH NINH THUẬN

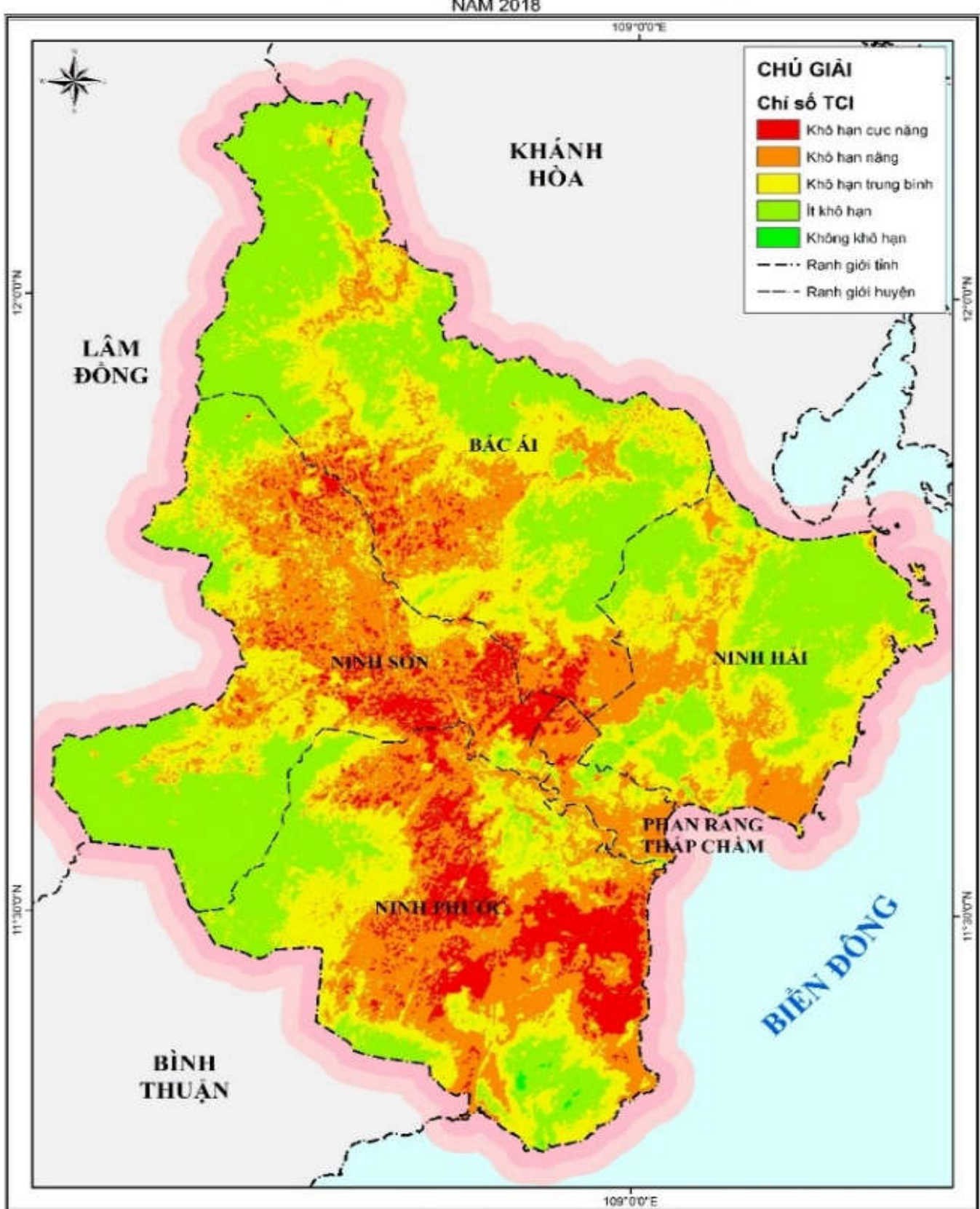

TYे 1. . 1:300 000 
(b) BẢN ĐÓ CHİ SÓ VCI TİNH NINH THUậN

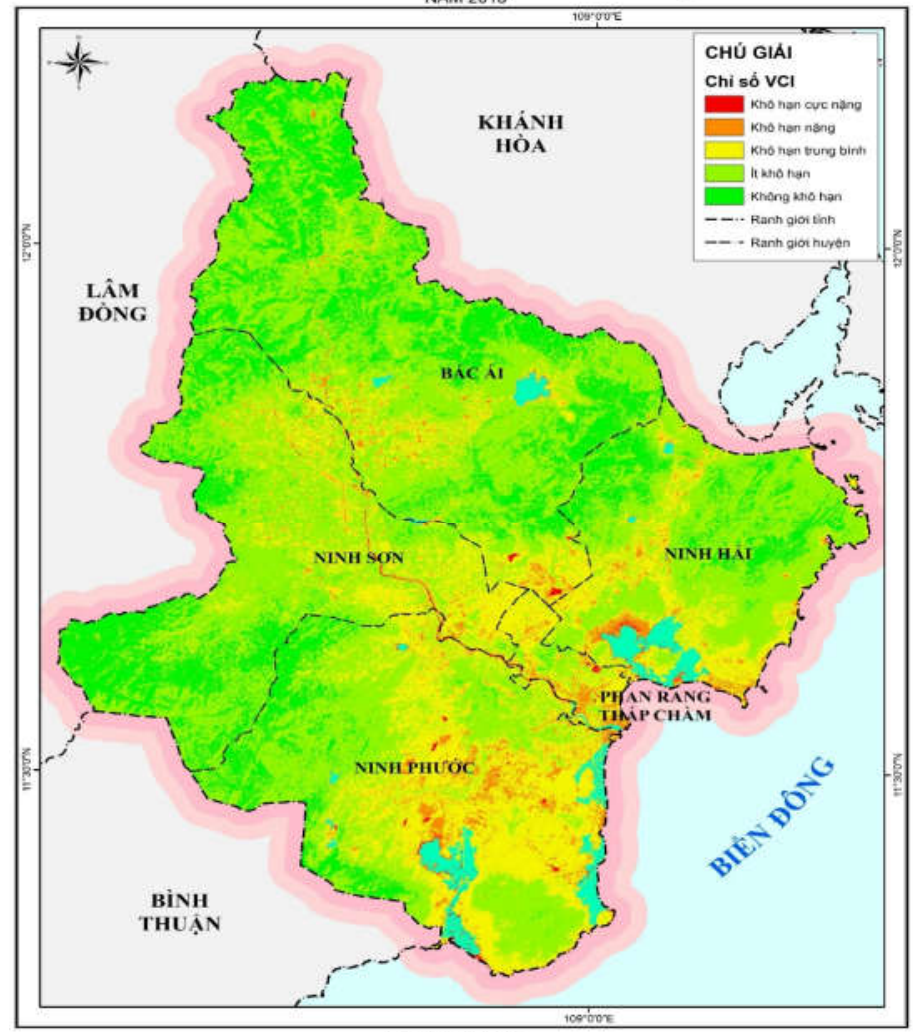

(c) BẢN Đò CHİ SÓ SAVI TíNH NINH THUậN

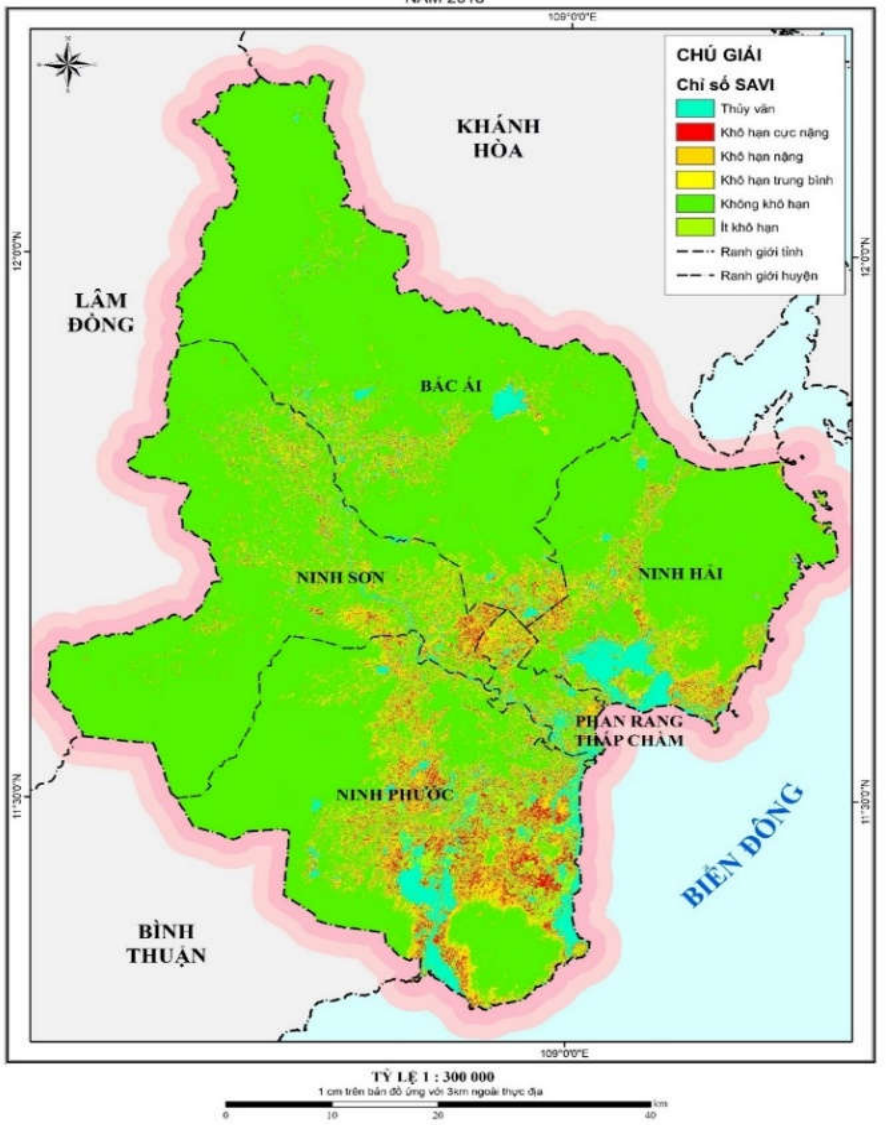


(d) BẢN Dó CHİ Só WSVI TÍNH NINH THUẬN

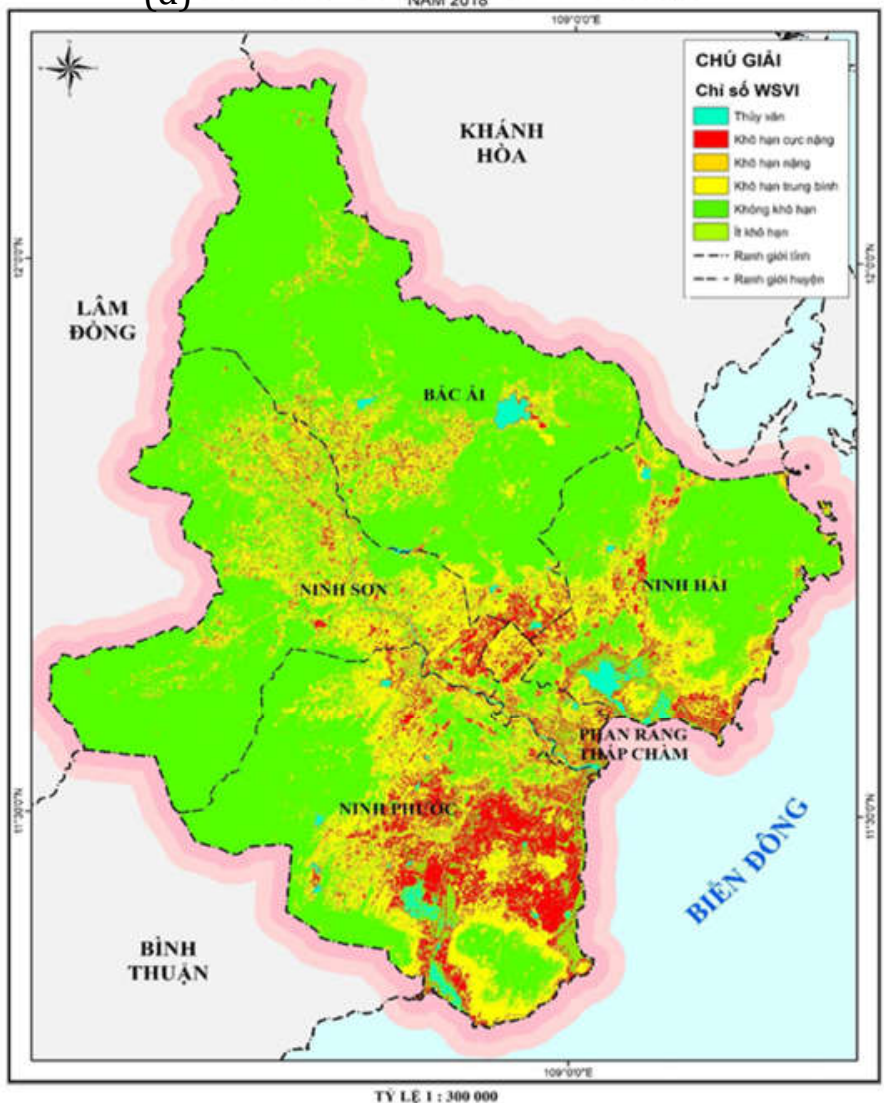

TYLL I : 300000

(e) BẢN Đồ CHİ Só TVDI TỉNH NINH THUận

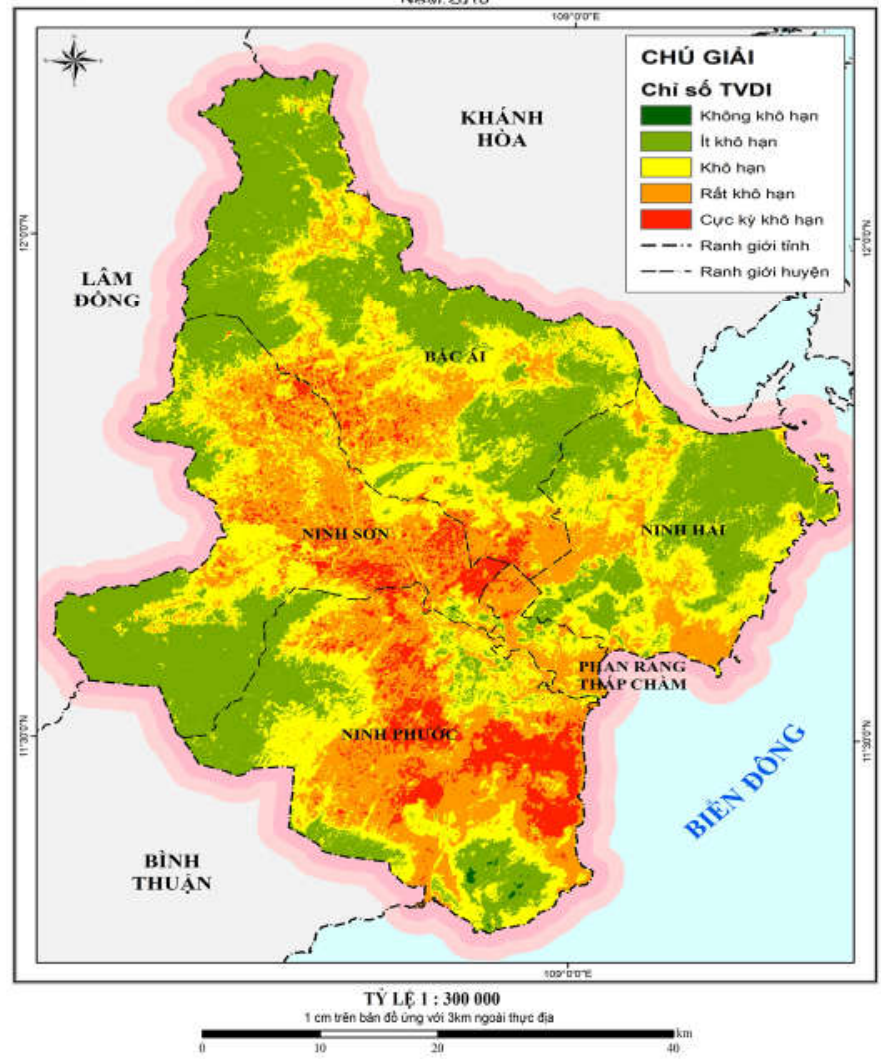




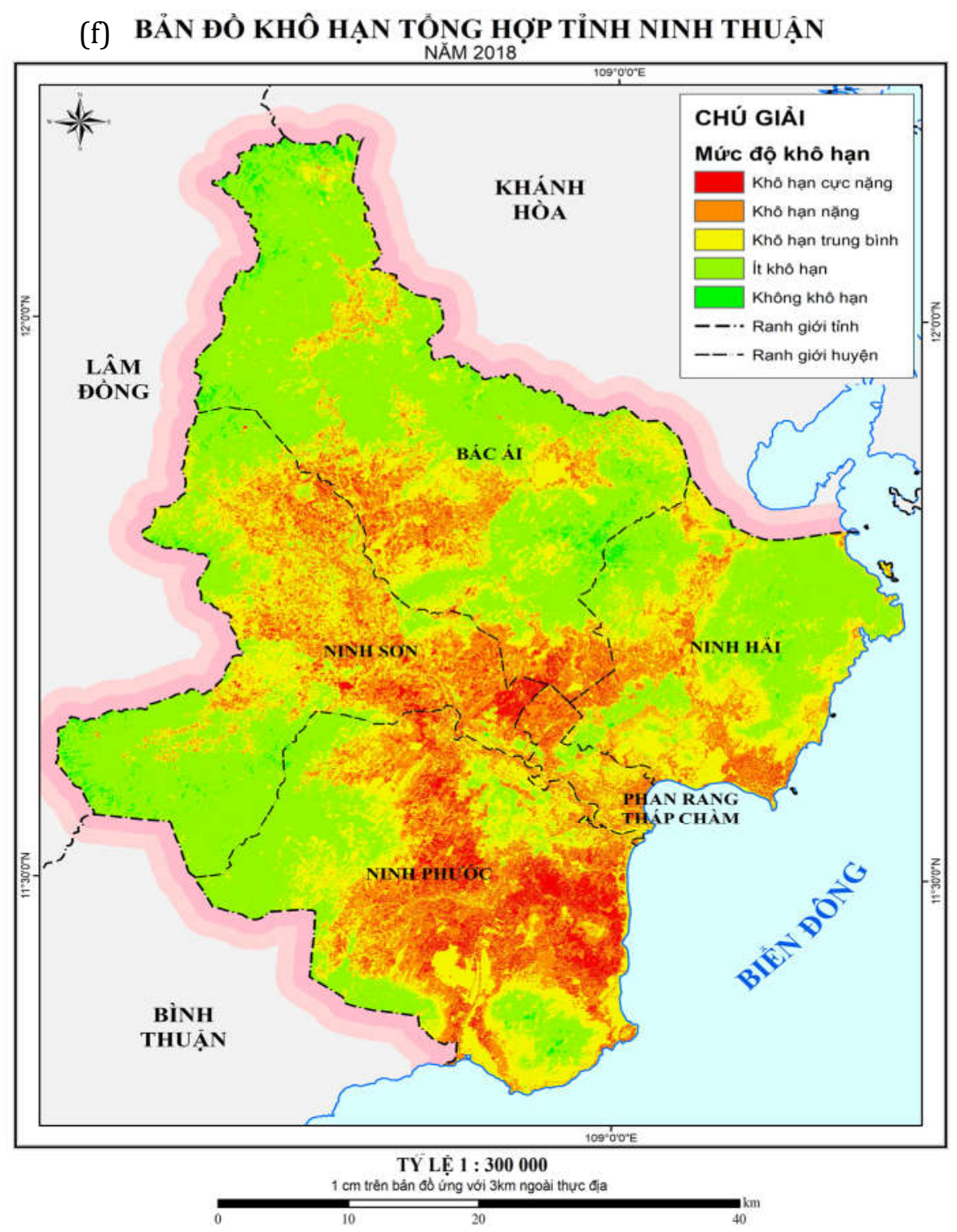

Hình 4. Các bản đồ thành phần các chỉ số.

TCI (a), VCI (b), SAVI (c), WSVI (d), TVDI (e) và bản đồ khô hạn tổng hợp tỉnh Ninh Thuận (f).

Độ chính xác của bản đồ khô hạn tổng hợp được kiểm tra bằng cách sử dụng một trong số các bản đồ khô hạn đã được thành lập cho khu vực Tây Nguyên và các tỉnh Nam Trung Bộ, trích cho khu vực nghiên cứu và phủ lên bản đồ khô hạn tổng hợp để đánh giá độ chính xác tổng thể. Mặc dù việc so sánh trực tiếp giữa hai bản đồ này không hoàn toàn hợp lệ do tính thời gian, không gian và tính năng động của các sự kiện mưa nắng, lượng bốc hơi,... tuy nhiên, kết quả so sánh cũng đã phản ánh được độ tin cậy của phương pháp. Bảng 3 cho thấy tại khu vực huyện Ninh Sơn diện tích hạn hán chềnh lệch ít nhất là $0,5 \%$, tại khu vực thành phố Phan Rang - Tháp Chàm diện tích hạn hán chênh lệch nhiều nhất là $12,9 \%$, điều này được giải thích bởi khu vực huyện Ninh Sơn phần lớn diện tích là đồi núi thấp chênh cao địa hình $<600$ m (so với Bác Ái chênh cao địa hình >1000 $\mathrm{m})$, còn khu vực thành phố Phan Rang - Tháp Chàm là nơi đông dân cư, mức độ bê tông hóa cao ảnh hưởng đến tính toán nhiệt độ là chỉ số liên quan trực tiếp đến xác định mức độ khô hạn.

\section{Kết luận}

Cách tiếp cận kết hợp chiết xuất thông tin địa không gian từ dữ liệu viễn thám, GIS và tích hợp 
Bảng 3. So sánh kết quả độ chính xác bản đồ khô hạn các khu vực.

\begin{tabular}{|c|c|c|c|c|c|}
\hline \multirow{2}{*}{ Khu vực } & $\begin{array}{c}\text { Diện tích tự } \\
\text { nhiên }\end{array}$ & \multicolumn{2}{|c|}{$\begin{array}{c}\text { Diện tích hạn hán trên } \\
\text { Bản đồ thành lập }\end{array}$} & \multicolumn{2}{|c|}{$\begin{array}{c}\text { Diện tích hạn hán trên } \\
\text { Bản đồ so sánh }\end{array}$} \\
\cline { 2 - 5 } & $\mathrm{km}^{2}$ & $\mathrm{~km}^{2}$ & $\%$ & $\mathrm{~km}^{2}$ & $\%$ \\
\hline Huyện Bác Ái & 1031,97 & 318 & 30,8 & 386 & 37,4 \\
\hline Huyện Ninh Sơn & 773,96 & 427 & 55,2 & 431 & 55,7 \\
\hline Huyện Ninh Hải & 571,26 & 111 & 19,5 & 130 & 22,7 \\
\hline Tp. Phan Rang - Tháp Chàm & 80,06 & 47 & 59,1 & 37 & 46,2 \\
\hline Huyện Ninh Phước & 904,55 & 545 & 60,3 & 493 & 54,5 \\
\hline
\end{tabular}

đa tiêu chí sử dụng phân tích thứ bậc AHP có thể được sử dụng hiệu quả để xác định khu vực hạn hán từ một số chỉ số cơ bản. Trong nghiên cứu này, mức độ khô hạn phụ thuộc phần lớn vào chỉ thị nhiệt độ, thực vật. Khô hạn nặng và rất nặng xảy ra phần lớn ở huyện Ninh Phước chiếm trên $60 \%$ diện tích (phù hợp với thực tiễn).

Kết quả khá hữu ích và nhanh chóng trong việc xác định các vùng "nguy cơ hạn hán" ở cấp địa phương, cũng có thể được sử dụng như là một công cụ để giải quyết mối quan tâm về nguy cơ khô hạn quy mô toàn quốc hoặc lớn hơn. Các bản đồ yếu tố thành phần liên quan còn có thể linh hoạt thay đổi tùy theo dữ liệu được cung cấp và tùy theo đặc điểm địa lý của khu vực nghiên cứu để tăng độ chính xác xác định khô hạn trong tương lai.

\section{Lò̀i cảm ơn}

Bài báo được hoàn thành với sự cho phép của chủ nhiệm và sử dụng một phần kết quả nghiên cứu từ đề tài: "Nghiên cứu phương pháp chiết xuất và tổng hợp các thông tin địa không gian từ dữ liệu viễn thám để thành lập bản đồ phục vụ đánh giá hiện trạng khô hạn tỉnh Ninh Thuận". Mã số T1917.

\section{Tài liệu tham khảo}

AghaKouchak, A.; Farahmand, A.; Melton, F. S.; Teixeira, J.; Anderson, M. C; Wardlow, Brian D.; and Hain, C. R., (2015). Remote sensing of drought: Progress, challenges and opportunities. NASA Publications, 151.

Bùi Quang Huy, Trần Trung Kiên, An Quang Hưng, Vũ Hữu Long, Nguyễn Vũ Giang, (2016). Ứng dụng tư liệu ảnh vệ tinh đa thời gian đánh giá nhanh mức độ khô hạn khu vực Tây Nguyên và các tỉnh Nam Trung Bộ. Viện Công nghệ Vũ trụ, Báo cáo kỹ thuật.

Eskinder Gidey, Oagile Dikinya, Reuben Sebego, Eagilwe Segosebe \& Amanuel Zenebe, (2018). Analysis of the long-term agricultural drought onset, cessation, duration, frequency, severity and spatial extent using Vegetation Health Index (VHI) in Raya and its environs, Northern Ethiopia. Environmental Systems Research 7, Article number: 13.

Hoàng Thanh Sơn, Vũ Thị Thu Lan, Nguyễn Quang Chiến, (2014). Đánh giá tác động của biến đổi khí hậu đến TNN mặt vùng khô hạn Ninh Thuận. Kỷ yếu hội nghị khoa học địa lý toàn quốc lần thứ 8, 648 - 653.

Lê Sâm, Nguyễn Đình Vượng, (2008). Nghiên cứu lựa chọn công thức tính chỉ số khô hạn và áp dụng vào việc tính toán tần xuất khô hạn năm ở tỉnh Ninh Thuận. Viện Khoa học và Thủy lợi miền Nam. Tuyển tập kết quả khoa học và công nghệ 2008.

Rosalena I. R., Rokhmatuloh, Revi Hernina, (2014). Water Supplying Vegetation Index (WSVI) Analysis for Drought Rate Mapping in Bogor Regency. IOP Conf. Series: Earth and Environmental Science 284 (2019). doi:10.1088/1755-1315/284/1/012014.

Saaty T.L., (1977). A scaling method for priorities in hierarchical structures. Journal of Mathematical Psychology 15, 234-281.

Trần Văn Tý, Đặng Thị Thu Hoài, Huỳnh Vương Thu Minh, (2015). Xây dựng bản đồ hạn hán đồng bằng sông Cửu Long trong bối cảnh biến đối khí hậu. Tạp chí Khoa học trường Đại học Cần Tho', số chuyên đề Môi trường và Biến đổi khí hậu, 226 - 233. 
Trịnh Lê Hùng, Đào Khánh Hoài, (2015). Ứng dụng viễn thám đánh giá nguy cơ hạn hán khu vực huyện Bắc Bình, tỉnh Bình Thuận. Tạp chí Khoa học Đại học Sư phạm Thành phố Hồ Chí Minh 5 (70).

Vũ Thị Thu Hằng, Trần Thanh Hà, (2013). So sánh một vài chỉ số hạn hán ở các vùng khí hậu Việt
Nam. Tạp chí khoa học Đại học Quốc gia Hà Nội, Khoa học Tự nhiên và Công nghệ 29(25), 51-57.

Willibroad Gabila Buma and Sang-Il Lee, (2019). Multispectral Image-Based Estimation of Drought Patterns and Intensity around Lake Chad, Africa. Remote Sens. 11, 2534. doi:10. $3390 /$ rs11212534. 